\title{
CEREBRAL ATROPHY IN MICROCEPHALIC COUSINS
}

\author{
BY \\ PETER E. SYLVESTER \\ From the Fountain Hospital, London
}

(RECEIVED FOR PUBLICATION MARCH 4, 1959)

'There are secrets in all families.'

GeORGE FARQUHAR

Microcephaly is one of the commonest findings in low-grade mental defectives (idiots and imbeciles). It is associated with different forms of encephalopathy. Rarely, it occurs in families; Brandon, Kirman and Williams (pending) found that 114 unselected cases of microcephaly had 166 siblings of whom nine were also microcephalic. However, its occurrence in siblings or other relatives does not necessarily imply the same cause, though, when the nature of the lesions is similar, the possibility of a single disease being involved becomes likely. This was so in the following two children, who presented at necropsy granular and cortical atrophy (ulegyria) of a pattern often thought to follow cerebral birth trauma. However, this could be excluded in one child and was not definitely established in the other. The findings are reported since similar cases with familial association have not been recorded in the literature.

\section{Family History}

The two children, both boys, were first cousins, and gentiles. The father of one (Case 1) and the mother of the other (Case 2) were twins. Enquiry into the family tree (Fig. 1) failed to reveal evidence of similar illnesses in other members.

Nine years after the birth of Case 1, a healthy sister was born, who at 1 year of age was found to be developing normally. There had been no other pregnancies.

The three surviving siblings of Case 2 were all healthy and intelligent at the ages of 13,10 and 2 years.

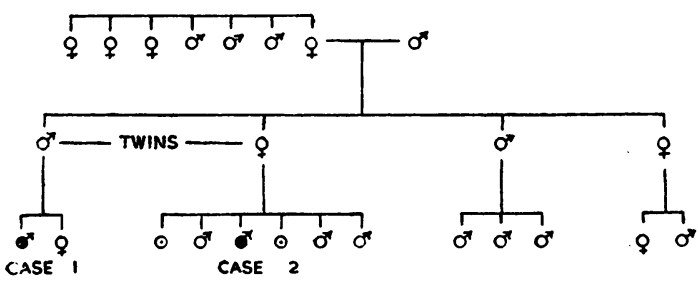

O= MISCARRIAGE

FIG. 1.-The family tree.
Case 1. He was the first child of a healthy mother, aged 24, and an unrelated, healthy father, aged 28. After a normal pregnancy, the infant was born at home. Presenting in the right occipito-posterior position and following a first stage lasting $36 \frac{1}{2}$ hours, the second stage was uneventful and he was delivered with ease, the umbilical cord being wound loosely round his neck. However, he suffered from white asphyxia for which he received several injections of nikethamide over three days. The birth weight was $6.0 \mathrm{lb}$. (2.73 kg.). Jaundice did not develop. He had convulsions on the third day of life. The skull circumference was not recorded.

At 8 months of age, it became obvious that the child was not developing normally. He could neither hold up his head nor sit. There were doubts about his vision. Convulsions, consisting of sudden momentary jerks of the whole body and sometimes accompanied by vomiting, occurred frequently by day and night. He was taken for medical advice, and found to have severe mental retardation. There were bilateral diffuse lenticular opacities of a non-specific type, and the lenses were partially subluxated upwards and outwards. The palate was high-arched. A radiograph of the skull was normal.

He made no progress. Other milestones, crawling, standing, walking and talking, were not passed. During his second year, tonic spasms of his whole body followed by twitchings of the face, eyes, limbs and circumoral cyanosis occurred, these episodes lasting about a minute. Following convulsions, he often had bouts of crying which were impossible to soothe and continued day and night for several weeks.

The lenticular opacities were needled on several occasions and he was thought to be partially sighted.

At one time he seemed to know his parents' voices, but this was the only suggestion that he could ever hear.

Bronchitis, tonsillitis, pneumonia and several bouts of pyrexia intervened up to the time of admission to the Fountain Hospital at 5 years 10 months, when he had another attack of pneumonia. He was then a helpless, emaciated, barely conscious idiot, without any sort of rapport. A number of vague, restless and purposeless movements were noted; occasionally he stretched himself and brushed his right hand across his face. He had contractures of the right hand and foot.

There was a marked strabismus and nystagmoid movements to the right. The pupils, the right smaller than the left, were central and reacted to light but not convergence. There were peripheral lenticular opacities. 
Lacking a blink reflex and ability to fix objects, he appeared to be completely blind. He did not react to a squeaky toy and, although the external and middle ears seemed normal, it was impossible to assess his auditory ability.

He was markedly hypotonic, and the tendon and abdominal reflexes could not be elicited. His I.Q. was 14 on the Vineland Scale.

His height was $40 \mathrm{in}$. $(1.02 \mathrm{~m}$.) and weight $28 \mathrm{lb}$. $\left(12 \cdot 7 \mathrm{~kg}\right.$.). The head circumference was $18 \frac{1}{2} \mathrm{in} .(47 \cdot 0 \mathrm{~cm}$.) average normal for age and sex being $51 \cdot 8 \mathrm{~cm}$. (Westropp and Barber, 1956). The cranial index was $0.73 \mathrm{~cm}$.

Radiography of the skull showed no bony abnormality. There was no albumen, sugar or phenylpyruvic acid in the urine.

He died suddenly at 5 years 11 months following a major fit during a meal.

Pathological Findings. The necropsy on the second day after death was performed by the coroner's pathologist. Death was due to severe subacute bilateral panpetrositis. Bronchopneumonia, with gross compensatory emphysema, was present at both bases, and terminal inhalation of stomach contents had occurred. The stomach was greatly distended and somewhat hypertrophic. A rather large liver showed numerous areas of focal necrosis. Apart from some congestion of the spleen and kidneys, and a small brain, other organs seemed normal.

The fixed brain, symmetrical in shape, with the cerebellum and brain stem, weighed $912 \mathrm{~g}$. (average normal for age: $1,243 \mathrm{~g}$.). Radiographically, the posterior horns of the lateral ventricles were slightly distended; there was no evidence of calcification. The superior temporal gyri were narrower than usual. At the right occipital pole occupying the tip, the medial aspect for

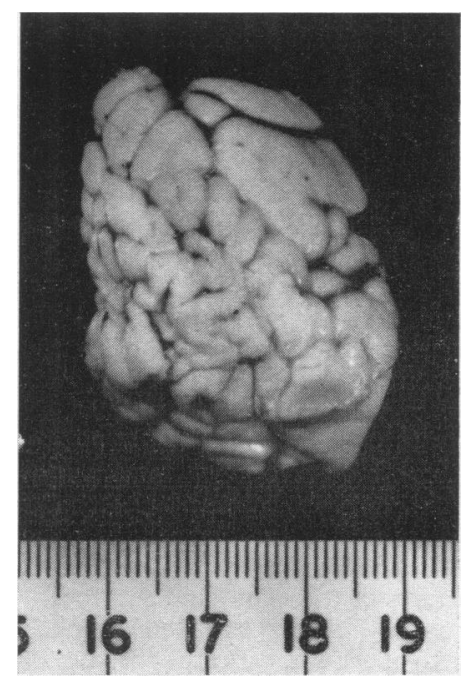

Fic; 2.-Case 1. C) tical atrophy at the tip of the right occipital lobe.
$3 \mathrm{~cm}$, and extending on to the medio-inferior margin for $1 \mathrm{~cm}$., there was macroscopic ulegyria with "cobblestone' appearance (Fig. 2). The left occipital pole looked normal. The ependyma was smooth and the meninges looked clear and could be stripped easily from the underlying cortex.

Histological Findings. Coronal sections of the frontal, temporal and occipital lobes, the basal ganglia, mid-brain, pons, medulla and cerebellum were embedded in celloidin, and sections stained by the usual neuropathological procedures-Nissl, Heidenhain, H.V.G., Mallory's P.T.A.H., Holzer, P.A.S., Greenfield's thionin, Nile blue sulphate and mucicarmine techniques. Frozen sections were used for Scarlet R, thionin, Holzer, von Kossa, Turnbull and Kultschitsky-Pal methods.

The most striking changes were in the occipital lobes where ulegyria affected several gyri above and below the post-calcarine sulcus (Fig. 3).

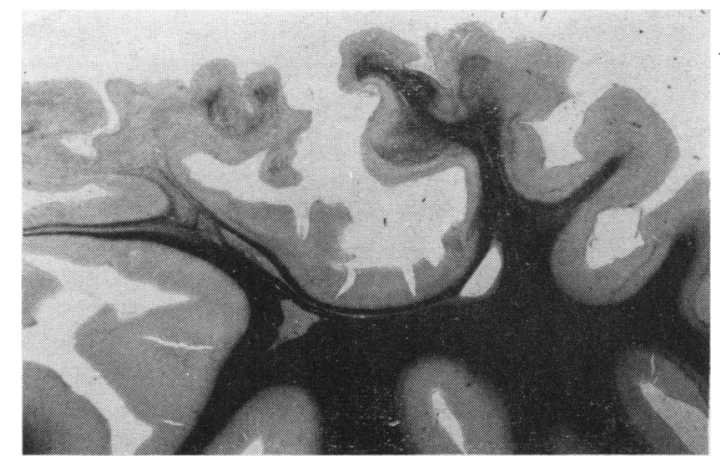

FIG. 3.-Case 1. Ulegyria with demyelinaticn around the postcalcarine sulcus. Kultschitsky-Pal $\times 3$.

Some of the gyri had been destroyed completely and the grey and white matter replaced by dense shrivelled glial scars, composed of three layers. The outermost layer was a rim of dense parallel glial fibres. The innermost layer consisted of a whorled knotty core of glial tissue with a network of collagen fibres-the remnants of blood vessels (Fig. 4). Between these two layers, glial strands ran, palisade fashion, at right-angles to the surface. Neither nerve cells nor myelin fibres had survived.

Less severely affected gyri showed incomplete destruction with many surviving nerve cells and myelin fibres. The profile of such a gyrus had a narrow stem surmounted by a large crown of apparently intact cortex with a normal cyto-architectonic structure. The stem was composed of a central core of glial tissue, which had replaced destroyed myelin tracts. Around this region some of the arcuate f.bres remained, thus outlining an area of gliosed white matter. The surrounding grey matter was considerably thinned, nerve cells were reduced in number, and fibrous astrocytes were increased. In some areas of the stem, nerve cell loss was complete, notably in small laminar scars (Fig. 5) affecting layers 3 


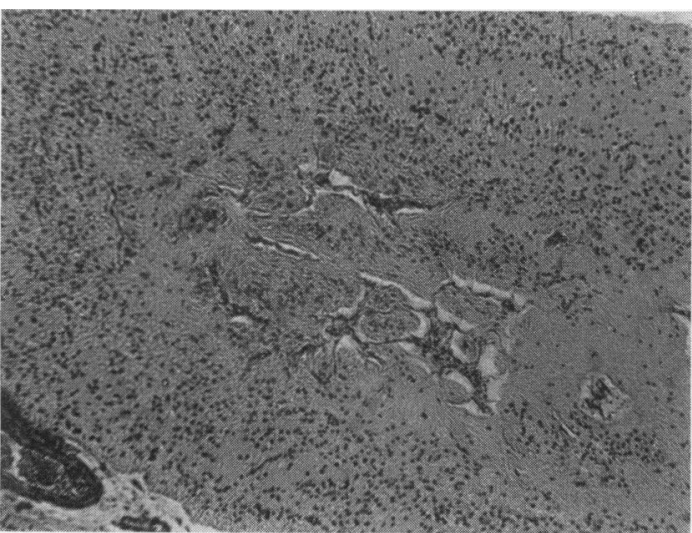

FIG. 4.-Case 1. Collagen tissue, the remnants of blood vessels, in the case of a destroyed gyrus. H.V.G. $\times 110$.

and 4. These small scars, semilunar in shape, were composed of a dense network of glial fibres from which glial strands radiated towards the surface, where they merged with a thick carpet of superficial glial fibres. Myelin fibres were absent from these scars, but those in adjacent areas were distorted. The cortical surface over these small scars was dimpled, thus accounting for the macroscopic appearance of granular atrophy.

Numerous metachromatic bodies were easily demonstrable in the white substance. They were small discrete globules much more numerous than the glial nuclei and varying in size from that of the nuclei to two or three times their size. They stained pink-violet by Greenfield's thionin method in celloidin sections and they were strongly P.A.S. positive. They stained with mucicarmine but not with Nile blue sulphate or Scarlet $\mathbf{R}$.

The cyto-architectonic structure of the basal ganglia was normal. The white matter, containing a number of 'mucocytes', was well myelinated.

There was evidence of damage in other areas of the brain, notably demyelination with glial replacement in the corona radiata, the adjacent grey matter being markedly gliosed.

Astrocytes were increased in the molecular layer of the cerebellar cortex and Bergmann's cells were also present, especially towards the apices of the leaflets. There was no alteration in size and number of the Purkinje cells. There was neither demyelination, loss of granular cells, nor abnormality of the dentate nuclei.

The frontal and temporal lobes appeared normal. The optic nerves were well myelinated. Abnormality was not noted either in the Ammon's horn or in the brain stem.

The meninges and the blood vessels outside the scarred areas were normal. The ependyma overlying the calcar avis in the dilated posterior horn was partly denuded of cells, and there was periventricular gliosis.

Calcium could not be demonstrated. Compound granular corpuscles containing neutral fat were scattered in the atrophic cortex and collected around neighbouring

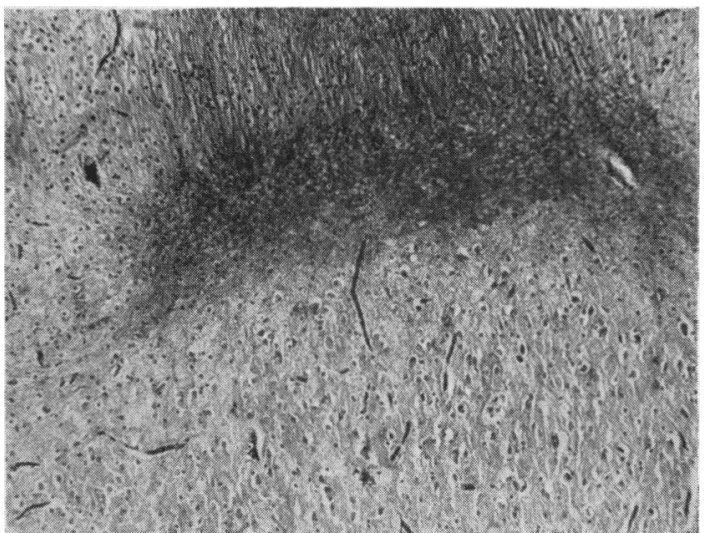

FIG. 5.-Case 1. A glial laminar scar in the grey matter. Holzer $\times 110$

blood vessels. Examination by polarized light failed to reveal doubly refractile material.

Case 2. He was the second child of a healthy mother, aged 26 , and an unrelated healthy father, aged 27 . The mother attended an antenatal clinic; her pregnancy was normal and her pelvis was considered adequate. Labour commenced at term and proceeded to a normal vertex delivery. The total duration of labour was 14 hours and 40 minutes and there was a post-partum loss of $5 \mathrm{oz}$. (135 ml.). The infant weighed $5 \mathrm{lb} .11 \mathrm{oz} .(2 \cdot 5 \mathrm{~kg}$.); his umbilical cord measured $20 \mathrm{in} .(50 \cdot 8 \mathrm{~cm}$.); his length was $19 \frac{1}{2}$ in. $(48.6 \mathrm{~cm}$.) and the head circumference $14 \mathrm{in}$. $(35.6 \mathrm{~cm}$.). Head moulding was thought to be absent. He was considered normal at birth and required minimal resuscitation. Complications were absent during the lying-in period and breast-feeding was satisfactorily established. Mother and child were discharged fit and well on the tenth day.

At 3 weeks of age he developed projectile vomiting after every feed. A diagnosis of congenital pyloric stenosis was made. A laparotomy was performed under $5 \%$ procaine local anaesthesia and open ether, but there was no evidence of pyloric 'tumour'. The post-operative period was stormy and vomiting continued. Slow improvement was achieved with atropine methonitrate and adjustment of feeds; nevertheless, vomiting was frequent. On the twenty-first day after operation he became cyanosed, tachypnoeic, and vomited copiously, and was placed in an oxygen tent. Ten days after this he developed a staphylococcal abscess of the thigh. Eventually his symptoms abated and he was discharged after 54 days in hospital.

Mental retardation was first suspected at nine months when he could not sit. Subsequently, he failed to pass other developmental milestones and never recognized his mother. Projectile vomiting continued. Epileptic fits developed, but there is no record of their character. $\mathrm{He}$ could not eat solid foods and, because of lack of progress, was again admitted to hospital at 23 months, when he 
was considered to be a blind, microcephalic mental defective. His head circumference was then $16 \frac{1}{2}$ in. $(41.9 \mathrm{~cm}$., average normal for age: $49 \cdot 1 \mathrm{~cm}$.). The back of his head was flattened. His reflexes and optic fundi were normal.

He was admitted to the Fountain Hospital at 4 years and 4 months, and classified as a microcephalic epileptic idiot with spastic diplegia. Feeble and helpless, he lay inertly in his cot with his legs partly drawn up and his right arm, flexed at the elbow and held rigidly against his body; occasionally he raised his left arm and stretched it. He drooled, resented being touched, and could neither sit nor hold up his head, flopping back when raised. He made no sounds other than a whimper.

His height was 34 in. $(0.89 \mathrm{~m}$.) and weight $20 \mathrm{lb}$. $\left(9 \cdot 1 \mathrm{~kg}\right.$.). The occipito-frontal circumference was $16 \frac{3}{4}$ in. $(42.5 \mathrm{~cm}$., average normal for age and sex being $52.7 \mathrm{~cm}$.). The cranial index was $0.78 \mathrm{~cm}$. There was neither strabismus nor nystagmus. The lenses were clear. Pupils were central and circular, reacting equally to light. It was difficult to determine whether he had any vision. The external and middle ears were normal and he seemed to hear, showing excitement such as struggling and threshing his arms about when a tambourine was sounded. The legs were hypotonic with unequal knee jerks, that on the right being exaggerated. The plantar responses were equivocal.

Radiography of the skull revealed no kony abnormalities other than microcephaly. The W.R. was negative. Phenylpyruvic acid was absent from the urine. His blood group was $\mathrm{O}, \mathrm{M} \mathrm{S} \mathrm{M} \mathrm{S}, \mathrm{P}+, \mathrm{cde} / \mathrm{cde}, \mathrm{Lu}(\mathrm{a}-)$, $\mathbf{K}-$, Le $(\mathbf{a}-, \mathbf{b}+)$, Fy $(\mathrm{a}-)$, Jk $(\mathbf{a}-)$. The cerebro-

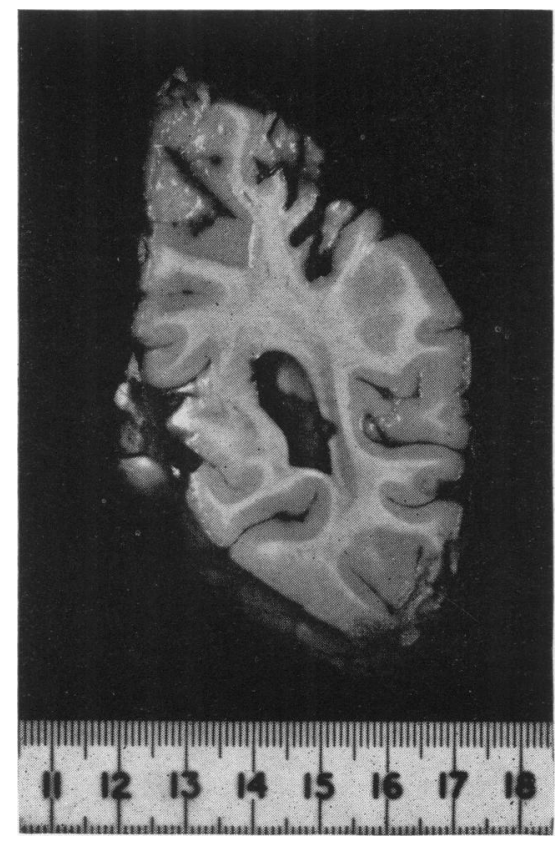

Fig.6.-Case 2. Cortical atrophy affecting the superior occipital gyrus.

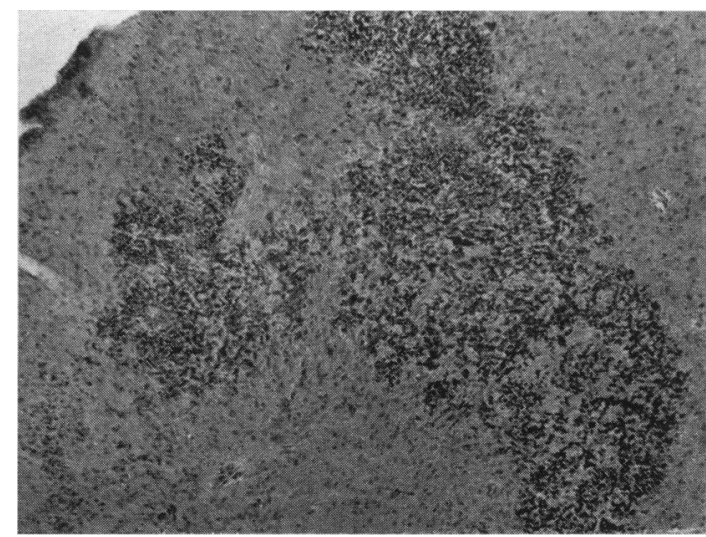

Fig. 7.-Case 2. Pseudo-calcium within the scar. Haematoxylin and carmine. $\times 110$.

spinal fluid was normal. An E.E.G., taken at 6 years 4 months, showed a right posterior focus of sharp waves, but the left side showed so little rhythmic activity that a large destructive lesion on that side was considered possible. The dominant regular activity was in the theta range and had a rather sharp form. No alpha rhythm was present.

During his stay in hospital he made no mental progress and seven to 11 fits occurred each year. He had several respiratory infections, succumbing finally to bronchopneumonia at 6 years 5 months. Three days before death, a succession of fits began, with vomiting of food, during which the face twitched especially round the mouth. At first the arms were spastic and stimulation caused clonic spasms; meanwhile the legs remained hypotonic. Within 24 hours the spasticity and irritability spread to the legs until, 12 hours before death, he became comatose.

Pathological Findings. At necropsy, on the day after death, the only significant findings, apart from those in the nervous system, were in the lungs and heart. Thick purulent sputum was present in the trachea and bronchi and in both lower lobes there were areas of lobular collapse, emphysema and bronchopneumonia. The foramen ovale was patent to a probe. Histologically, bronchopneumonia was confirmed. There were areas of alveolar collapse, inhalation and inflammatory pneumonia, alternating with areas of emphysema.

The fixed brain, rounded and symmetrical in shape, with the cerebellum and brain-stem weighed $826 \mathrm{~g}$. (average normal for age: $1,235 \mathrm{~g}$.). It was firm to touch, especially in the occipital poles, which did not completely overlap the cerebellum. Over the lateral aspect of both occipital lobes there was ulegyria, more marked on the left side. The corpus callosum was thinned in its posterior third. The basal ganglia seemed normal. Radiographically, there was dilatation of the posterior horns of the lateral ventricles; calcification was not seen. The ependyma was smooth and there was no naked-eye abnormality of the meninges. 
Histological Findings. Representative sections were treated as in the previous case. In addition, sections from the parietal lobe and the spinal cord at the cervical, thoracic and lumbar levels were available.

As in Case 1, the most striking changes were in the occipital lobes where sclerosis affected several gyri in the external aspect of the lobes (Fig. 6). All layers of the sclerosed cortex were diseased. Nerve cells and white matter were destroyed and replaced by dense glial scars containing streaks of collagen, which were all that remained of obliterated blood vessels. Unlike Case 1, there were several deposits of pseudo-calcium within the scars (Fig. 7).

Several cysts, lined by dense glial tissue, were present in the sclerotic areas.

Demyelination, accompanied by fine gliosis, was present in the white matter adjacent to the cortical sclerosis.

Granular atrophy affected the cortex of the occipital lobe (Figs. 8 and 9), especially the depths of the sulci. It was more pronounced than in Case 1. Nerve cells and myelin fibres were absent from the glial scars, the more discrete of which extended toothlike from the surface into the grey matter; the intervening grey matter contained both nerve cells and myelin fibres.

There was a universal focal loss of nerve cells, with astrocytic replacement, in layers 3 and 4 throughout the occipital cortex. The visual cortex around the postcalcarine sulcus was affected by this nerve cell loss.

The meninges overlying the cortical scars were not thickened and contained normal-looking vessels. Haemorrhage was present in one area over the cortical scars. The normal-looking pia over the ulegyric scars was separated from the cortex by a thin layer of structureless picrophilic material.

Unlike Case 1, there was a widespread focal loss of nerve cells in layers 3 and 4 in the frontal lobe and also in the parietal cortex and the grey matter of the insula. 'Plaques fibromyéliniques' and marginal gliosis were noted in the parietal cortex.

The cyto-architectonic pattern of the basal ganglia was normal and there was no demyelination. Numerous metachromatic bodies were demonstrated in the white

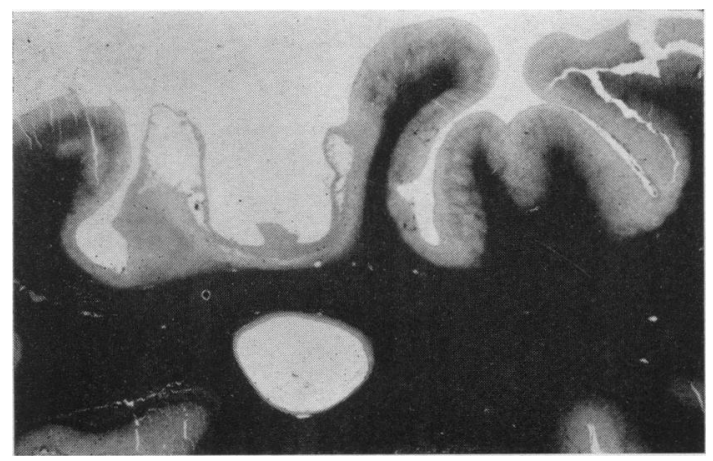

Fig. 8.-Case 2 Cortical atrophy of the occipital lobe with cyst formation. Kultschitsky-Pal $\times 3$. matter and, although they varied in size, many were large, about ten times the size of those in Case 1.

The cerebellum was well formed, and microscopically the organ looked normal.

The optic tracts were well myelinated and the cellular components of the external geniculate bodies were normal.

The Ammon's horn, brain stem and the spinal cord were normal.

\section{Discussion}

The type of lesions described are commonly thought to follow cerebral birth injury but this was absent in Case 2. Despite certain minor differences, the great measure of clinical and pathological similarity in the two cases makes a common disease likely.

Van Bogaert (1950) reported marbling in the thalamo-striate region of a brother and sister in whose family there were epileptic and mentally retarded members. Marbling of the basal ganglia and cortical atrophy are variants of scarring which is often thought to follow cerebral birth injury, and in van Bogaert's cases laminar necrosis and 'plaques fibromyéliniques' were demonstrated in the cortices. However, scarring may be produced in different ways and, in fact, there was no suggestion of a cause of cerebral birth injury other than the prolonged first stage of labour in Case 1.

In considering possible genetic factors, the opacities of the lenses and their subluxation in Case 1 may be important. According to Sorsby (1953), these lesions are usually due to dominant genes, but occasionally recessive inheritance occurs and this may have been the explanation for the present cases.

The head circumference of a microcephalic child may be within normal limits at birth. This was so in Case 2, whose head circumference at birth was 14 in. $(35.6 \mathrm{~cm}$.), but at 23 months it was $41.9 \mathrm{~cm}$.

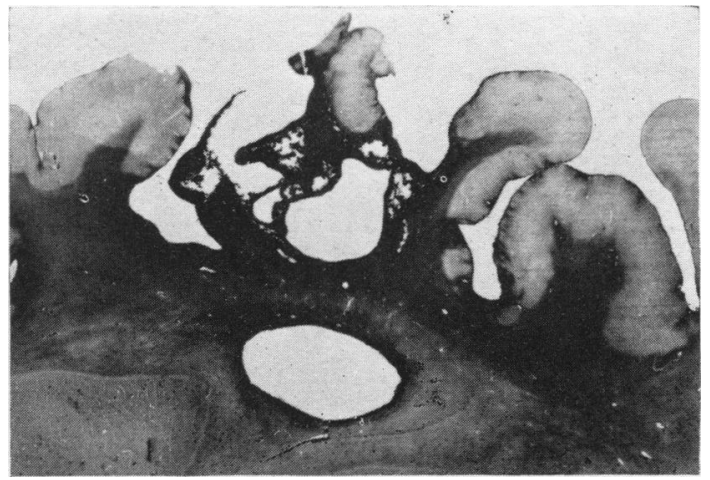

FIG. 9-Case 2. Dense gliosis in a section at a similar level to Fig 8. Holzer $\times 3$. 
at 4 years and 4 months it was $42.5 \mathrm{~cm}$.; and at 6 years and 5 months it was $44.0 \mathrm{~cm}$. These last three figures are below three standard deviations from the mean for the age and sex.

\section{Summary}

The clinical and pathological aspects of microcephaly in two first cousins are described. Both children were blind, epileptic idiots. After death it was found that their brains were micrencephalic and showed cortical atrophy (ulegyria). Bilateral scarring affected the occipital lobes more than other parts of the hemispheres. In one child there was also widespread focal loss of cells throughout both hemispheres. Both brains showed laminar scars in the grey matter. One child had lenticular subluxation and opacities. It is suggested that the pathological changes in the brains might have been due to recessive inheritance.

Dr. B. H. Kirman gave me advice and Dr. L. Crome encouraged and guided me; Miss M. F. Craib gave valuable help with the family and social studies and members of other hospitals were most helpful in giving information. To all these I owe my thanks.

\section{REFERENCES}

Bogaert, L. van (1950). Mschr. Psychiat. Neurol., 120, 169. Kirman, B. H., Williams, C. E. and Brandon, M. W. G. (1959). J. ment. Sci. In the press.

Sorsby, A. (1953), Clinical Genetics. Butterworth. London. Westropp, C. K. and Barber, C. R. (1956). J. Neurol. Neurosurg. Psychiat., 19. 52. 